\title{
ESTIMATION OF STATURE FROM LOWER LIMB MEASUREMENTS BY REGRESSION ANALYSIS IN NORTH-WEST INDIAN POPULATION
}

\author{
Hitesh Chawla, Ashish Tyagi, Sandeep Dara, Aravindan U.
}

\begin{abstract}
The aim of the study was to estimate the stature from lower limb parameters in the north-west population of India and to know whether a significant correlation exists between the stature and various lower limb dimensions and to further derive regression formulae for estimation of stature from various lower limb segments.

Materials and methods: the study was conducted on medical students age ranged between 18 to 28 years, which comes chiefly from north-west part of India. Only the subjects willing to participate in the study and given their written informed consent were included in the study group. The students having any obvious physical deformity were excluded from the study. Correlations between various lower limb parameters and stature were determined by using the Pearson's correlation test. Sex-specific linear regression equations for stature estimation were developed using the lower limb measurements. The multiple regressions equations were produced based on various combinations of the parameters by stepwise regression analysis.
\end{abstract}

Results: the Pearson's correlation in combined group showed good correlations between lower limb parameters and stature. There was no statistically significant difference between known stature and estimated stature by using paired Ttest for both right and left side in a group consisting of both sexes and in males ( $p>0.05)$.

Conclusion: from the parameters, lower limb length and foot length had shown strong positive correlations with stature in the north-west Indian population

Keywords: identification, stature, lower limb, foot length, foot breadth, leg length

How to cite:

Chawla, H., Tyagi, A., Dara, S., Aravindan, U. (2022). Estimation of stature from lower limb measurements by regression analysis in north-west Indian population. ScienceRise: Medical Science, 1 (46), 37-43. doi: http://doi.org/10.15587/2519-4798.2022.252808

\section{Introduction}

Identification or determination of individuality is the fundamental right of human being whether live or dead. Mutilated bodies in day-to-day practice of forensic pathology are not an uncommon occurrence, which could either be due to man-made or natural disaster. Even criminals used to dismember the dead body in a brutal act of homicide to conceal the crime. Animals may also mutilate the dead body, especially when the dead body is exposed in an open place. Many a time's only body parts are available with forensic pathologists to determine the cause of death and to establish the individuality of the person.

Estimation of the stature is one of the most imperative elements in the identification of an individual [1]. The stature of an individual is an inherent characteristic; its estimate is considered to be an important assessment in the identification of unknown human remains [2].

Various body parts could be used in estimation of stature. Several studies have been conducted in different regions of the country and worldwide to estimate stature from various body segments. It was also opined more than 50 years ago that regional studies on stature estimations were very much needed due to racial and ethnic variations present indifferent regions of the world [3]. Stature estimation may be specifically derived from each population. Specific regression for specific population is important to account for inherent population variations such as genetic and environmental factors [4]. There are inter-racial \& inter-geographical differences in the measurements \& their correlation with the stature. India is comprised of a substantial number of ethnic and indigenous groups, and its ethnic and genetic diversity is enormous. It has the largest number of indigenous people in the world [5].

The aim of the present study was to estimate stature from lower limb parameters in the north-west population of India and to know whether a significant correlation exists between the stature and various lower limb dimensions and to further derive regression formulae for estimation of stature from various lower limb segments.

\section{Materials and methods}

The present cross-sectional study was conducted at the Department of Forensic Medicine in a tertiary care centre of Southern Haryana. Institutional Ethical committee (EC/OA-04/2019 dated 19/04/2019, SHKM Government Medical College, Nalhar) approval was obtained before initiation of the study. The study was conducted on 200 medical students age ranged between 18 to 28 years $(21.09 \pm 1.79)$, which comes chiefly from north- 
west part of India. Only the subjects willing to participate in the study and given their written informed consent were included in the study group. The students having any obvious physical deformity were excluded from the study. The following measurements were taken and noted down in the prescribed proforma:

\subsection{Stature}

The height of the individual was measured in centimetres. The subjects were made to stand in an erect posture on a stadiometer with their feet axis parallel or slightly divergent, head balanced on neck in Frankfurt Horizontal Plane and hands hang down. Before taking measurements, it was ensured that the subjects were not wearing any headgear or footwear. The sliding horizontal head piece of the stadiometer was made to contact the top of head and height was recorded in centimetres.

\subsection{Lower limb length}

The lower limb length was measured as a distance from the anterior superior iliac spine to the floor on its lateral side. The measurements were taken with the subject standing in neutral position after removing their shoe and socks. The measuring tape with gradation in centimetres and inches was used to measure the lower limb length.

\subsection{Knee to ankle length}

Knee to ankle length was taken as a distance between the top of the patella and the lateral malleolus. The subject was made to sit on a stool thereby making his knee flex at 90 degree angle and resting his foot on a foot rest. The measurement was taken with the help of measuring tape.

\subsection{Foot length}

Foot length was taken as the distance from the most prominent part of the heel backward to the most distal part of the longest toe (2nd or 1st, whichever in the particular subject). Digital sliding vernier caliper was used to measure the length of foot. The caliper was horizontally placed along the inner border of the foot.

\subsection{Foot breadth}

Foot breadth was measured as the distance between most prominent of the inner side of the foot (meta- tarsal-tibiale) which is the anterior epiphyses (distal) of the 1st metatarsal, and the joint of the anterior epiphyses of the 5th metatarsal, the most prominent of the outer side (metatarsal-fibulare). The measurements were taken with the subject standing erect with their foot resting on footrest. Digital sliding vernier caliper was used to measure the breadth of foot.

All the measurements were taken in centimetres up to two decimals. The measurements were taken each day at a fixed time between 2:00-3:00 PM to eliminate the discrepancies due to diurnal variation and by the same observer every day to avoid intra-observer error in methodology. As the technical errors could significantly affect accuracy and reliability; therefore, the instruments were checked regularly for accurate readings. Before proceeding for the data collection, a pilot study was carried out to get the measure of precision and reliability of obtaining the various lower limb measurements in question. The lower limb dimensions to be used in the study were taken on two different evaluation days by the same observer on the same 10 subjects. The measurements recorded during the pilot study were the same on both the occasions.

The data was statistically analyzed using IBM SPSS Statistics Version 20.0 for Windows (Armonk, NY: IBM Corp). The p-value of $<0.05$ was considered statistically significant. Correlations between lower limb parameters and stature were determined by using the Pearson's correlation test. Sex-specific linear regression equations for the estimation of stature were developed using the lower limb measurements. The correlation coefficient $(R)$, coefficient of determination $(R)^{2}$, and standard error of estimate (SEE) were calculated. The multiple regressions equations were produced based on various combinations of the parameters by stepwise regression analysis. The comparison between known and estimated statures was done by using paired T-test.

\section{Results}

A total of 200 students participated in the study comprising of 112 males and 88 females. The mean age for males in this study was 21.30 years and 20.82 years in females. The descriptive statistics for age, stature, and various lower limb dimensions for both sides in males and females is depicted in Table 1.

Table 1

Descriptive statistics for lower limb dimensions, age and stature in males and females

\begin{tabular}{|l|c|c|c|c|c|c|c|c|}
\hline \multirow{2}{*}{ Parameter } & \multicolumn{4}{|c|}{ Males $(\mathrm{n}=112)$} & \multicolumn{4}{c|}{ Females $(\mathrm{n}=88)$} \\
\cline { 2 - 10 } & Mean & SD & Min & Max & Mean & SD & Min & Max \\
\hline Age & 21.30 & 1.61 & 18 & 28 & 20.82 & 1.98 & 18 & 27 \\
\hline Height & 174.64 & 5.66 & 162 & 189 & 161.43 & 5.73 & 148 & 175 \\
\hline LLR & 101.45 & 7.23 & 80 & 116 & 93.63 & 6.16 & 74.50 & 108 \\
\hline LLL & 101.67 & 7.21 & 80 & 117 & 93.60 & 6.14 & 74.50 & 108 \\
\hline KAR & 45.07 & 8.14 & 37 & 108 & 40.29 & 3.11 & 32 & 46.50 \\
\hline KAL & 45.16 & 8.09 & 37 & 108 & 40.18 & 3.21 & 32 & 46 \\
\hline FLR & 25.13 & 2.92 & 10 & 30 & 23.31 & 1.62 & 20 & 27 \\
\hline FLL & 25.21 & 2.97 & 10 & 30.50 & 23.36 & 1.57 & 20 & 27 \\
\hline FBR & 9.80 & 0.94 & 7.80 & 13 & 9.03 & 1.10 & 6.50 & 11.50 \\
\hline FBL & 9.83 & 0.93 & 7.80 & 13 & 9.07 & 1.06 & 6.50 & 11.00 \\
\hline
\end{tabular}

Note: LLR - Lower limb right; LL - Lower limb left; KAR - Knee ankle right; KAL - Knee ankle left; FLR - Foot length right; FLL - Foot length left; FBR - Foot breadth right; FBL - Foot breadth left 
The Pearson's correlation in combined group showed good correlations between lower limb parameters and stature, in which LLR exhibited the highest correlation $(r=0.659)$ followed by LLL, FLL, FLR, KAL, KAR, FBL and FBR and FH. The correlation between stature and foot breadth on the right side in females was not significant $(\mathrm{r}=0.194)$. Rest all lower limb parameters showed significant correlation with stature in both males and females. The Pearson's correlation between lower limb parameters and stature in males, females and a group consisting of both sexes is depicted in Table 2 .

A summary of linear regressions in males, females and a group consisting of both sexes is depicted in Table 3. By employing the linear regression equation, the stature can be approximated from mutilated or fragmen- tary body remains by using the regression: $y$ (stature) $=\mathrm{b}$ (constant) + a (regression coefficient of the independent parameter) $x$. The regression in a group consisting of both sexes showed that LLR and LLL have a coefficient of determination $\left(\mathrm{R}^{2}\right)$ of $42 \%$. This means that $42 \%$ of variation was contributed by the parameters, while the remaining $58 \%$ of variation was due to random error (Table 3). The variance was subsequently reduced for each parameter that is, FLR, FLL (26\%), KAL (19\%), KAR $(18 \%)$, FBL $(17 \%)$ and FBR $(16 \%)$ respectively. The regression based on LLR in males, females and a group consisting of both sexes showed the lowest standard error of estimation (SEE) i.e. 5.21, 4.39 and 5.94 respectively, as compared to all other parameters (Table 3).

Table 2

The Pearson's correlation analysis between lower limb parameters and stature

\begin{tabular}{|c|c|c|c|c|c|c|}
\hline \multirow{2}{*}{ Parameter } & \multicolumn{2}{|c|}{ Males } & \multicolumn{2}{c|}{ Females } & \multicolumn{2}{c|}{ Combined } \\
\cline { 2 - 7 } & $\mathrm{R}$ & $\mathrm{p}$-value & $\mathrm{R}$ & $\mathrm{p}$-value & $\mathrm{R}$ & $\mathrm{p}$-value \\
\hline LLR & $0.400 * *$ & 0.000 & $0.647 * *$ & 0.000 & $0.659 * *$ & 0.000 \\
\hline LLL & $0.381 * *$ & 0.000 & $0.626 * *$ & 0.000 & $0.655 * *$ & 0.000 \\
\hline KAR & $0.307 * *$ & 0.001 & $0.268 *$ & 0.012 & $0.431 * *$ & 0.000 \\
\hline KAL & $0.302 * *$ & 0.001 & $0.260 *$ & 0.014 & $0.438^{* *}$ & 0.000 \\
\hline FLR & $0.332 * *$ & 0.000 & $0.616 * *$ & 0.000 & $0.511 * *$ & 0.000 \\
\hline FLL & $0.342 * *$ & 0.000 & $0.626^{* *}$ & 0.000 & $0.516 * *$ & 0.000 \\
\hline FBR & $0.259 * *$ & 0.006 & 0.194 & 0.070 & $0.408 * *$ & 0.000 \\
\hline FBL & $0.268 * *$ & 0.004 & $0.226 *$ & 0.034 & $0.420 * *$ & 0.000 \\
\hline
\end{tabular}

Note: $* *-p<0.01 ; *-p<0.05$

Table 3

Linear regression equations for stature $(\mathrm{cm})$ estimation in males, females and a group consisting of both sexes

\begin{tabular}{|c|c|c|c|c|}
\hline Parameter & Equation & $\mathrm{R}$ & $\mathrm{R}^{2}$ & SEE \\
\hline \multicolumn{5}{|c|}{ Male } \\
\hline LLR & $142.885+0.313$ LLR & 0.40 & 0.16 & 5.21 \\
\hline LLL & $144.253+0.299$ LLL & 0.38 & 0.14 & 5.25 \\
\hline KAR & $165.023+0.213 \mathrm{KAR}$ & 0.30 & 0.09 & 5.41 \\
\hline KAL & $165.104+0.211 \mathrm{KAL}$ & 0.30 & 0.09 & 5.41 \\
\hline FLR & $158.436+0.645$ FLR & 0.33 & 0.11 & 5.36 \\
\hline FLL & $158.211+0.652 \mathrm{FLL}$ & 0.34 & 0.11 & 5.34 \\
\hline FBR & $159.458+1.549 \mathrm{FBR}$ & 0.25 & 0.06 & 5.49 \\
\hline FBL & $158.585+1.633 \mathrm{FBL}$ & 0.26 & 0.07 & 5.47 \\
\hline \multicolumn{5}{|c|}{ Female } \\
\hline LLR & $105.082+0.602$ LLR & 0.64 & 0.41 & 4.39 \\
\hline LLL & $106.801+0.584$ LLL & 0.62 & 0.39 & 4.49 \\
\hline KAR & $141.535+0.494$ KAR & 0.26 & 0.07 & 5.55 \\
\hline KAL & $142.778+0.464 \mathrm{KAL}$ & 0.26 & 0.06 & 5.56 \\
\hline FLR & $110.585+2.181$ FLR & 0.61 & 0.37 & 4.54 \\
\hline FLL & $107.977+2.288 \mathrm{FLL}$ & 0.62 & 0.39 & 4.49 \\
\hline FBR & $152.280+1.013 \mathrm{FBR}$ & 0.19 & 0.02 & 5.65 \\
\hline FBL & $150.409+1.214 \mathrm{FBL}$ & 0.22 & 0.04 & 5.61 \\
\hline \multicolumn{5}{|c|}{ Combined } \\
\hline LLR & $96.874+0.734$ LLR & 0.65 & 0.42 & 5.94 \\
\hline LLL & $96.679+0.725$ LLL & 0.65 & 0.42 & 6.57 \\
\hline KAR & $145.323+0.547 \mathrm{KAR}$ & 0.43 & 0.18 & 7.85 \\
\hline KAL & $145.044+0.554 \mathrm{KAL}$ & 0.43 & 0.19 & 7.82 \\
\hline FLR & $127.128+1.714$ FLR & 0.51 & 0.26 & 7.48 \\
\hline FLL & 127.016 + 1.714 FLL & 0.51 & 0.26 & 7.46 \\
\hline FBR & $137.905+3.269 \mathrm{FBR}$ & 0.40 & 0.16 & 7.95 \\
\hline FBL & $136.017+3.454 \mathrm{FBL}$ & 0.42 & 0.17 & 7.90 \\
\hline
\end{tabular}


The regressions obtained by the multiple regression analysis for all four parameters by using various combinations for both left and right side in males, females and a group consisting of both sexes has been depicted in Table 4. In combined group, the multiple regressions showed lower SEE (5.70-7.27) than that in linear regressions (5.94-7.95) (Table 3).

The regressions based on LLR, KLR, FLR and FBR showed the lowest SEE in both males and females (4.83 and 3.69 respectively) $\mathrm{p}<0.001$ which was highly significant. The mean difference between known stature and estimated stature was $0.05 \mathrm{~cm}$ for both right and left side in males. The mean difference between known stature and estimated stature was higher in females for right side $(3.8 \mathrm{~cm})$ as compared to left side $(0.20 \mathrm{~cm})$ (Table 5$)$.

There was no statistically significant difference between known stature and estimated stature by using paired T-test for both right and left side in a group consisting of both sexes and in males $(p>0.05)$. While in females, statistically significant difference $(p=0.000)$ was observed in known stature and estimated stature for right side (Table 6).

Table 4

Multiple regression equations for stature $(\mathrm{cm})$ estimation in males, females and a group consisting of both sexes

\begin{tabular}{|c|c|c|c|}
\hline Equation & $\mathrm{R}$ & $\mathrm{R}^{2}$ & SEE \\
\hline \multicolumn{4}{|l|}{ Male } \\
\hline $128.215+0.217 \mathrm{LLL}+0.181 \mathrm{KAL}+0.440 \mathrm{FLL}+0.513 \mathrm{FBL}$ & 0.53 & 0.28 & 4.87 \\
\hline $144.531+0.194 \mathrm{KAL}+0.551 \mathrm{FLL}+0.758 \mathrm{FBL}$ & 0.46 & 0.21 & 5.08 \\
\hline $151.236+0.537 \mathrm{FLL}+1.004 \mathrm{FBL}$ & 0.37 & 0.14 & 5.29 \\
\hline $127.360+0.240 \mathrm{LLR}+0.188 \mathrm{KAR}+0.453 \mathrm{FLR}+0.309 \mathrm{FBR}$ & 0.54 & 0.29 & 4.83 \\
\hline $145.273+0.199 \mathrm{KAR}+0.559 \mathrm{FLR}+0.649 \mathrm{FBR}$ & 0.46 & 0.21 & 5.09 \\
\hline $152.017+0.532 \mathrm{FLR}+0.944 \mathrm{FBR}$ & 0.36 & 0.13 & 5.32 \\
\hline \multicolumn{4}{|l|}{ Female } \\
\hline $77.771+0.425 \mathrm{LLL}+0.156 \mathrm{KAL}+1.615 \mathrm{FLL}-0.009 \mathrm{FBL}$ & 0.76 & 0.58 & 3.78 \\
\hline $102.422+0.207 \mathrm{KAL}+2.205 \mathrm{FLL}-0.093 \mathrm{FBL}$ & 0.63 & 0.40 & 4.50 \\
\hline $107.799+2.276 \mathrm{FLL}+0.050 \mathrm{FBL}$ & 0.62 & 0.39 & 4.51 \\
\hline $76.187+0.449 \mathrm{LLR}+0.238 \mathrm{KAR}+1.523 \mathrm{FLR}-0.211 \mathrm{FBR}$ & 0.77 & 0.60 & 3.69 \\
\hline $102.844+0.285 \mathrm{KAR}+2.130 \mathrm{FLR}-0.284 \mathrm{FBR}$ & 0.63 & 0.40 & 4.51 \\
\hline $110.949+2.204$ FLR - 0.101 FBR & 0.61 & 0.38 & 4.56 \\
\hline \multicolumn{4}{|c|}{ Combined } \\
\hline $77.864+0.507 \mathrm{LLL}+0.312 \mathrm{KAL}+0.800 \mathrm{FLL}+0.868 \mathrm{FBL}$ & 0.76 & 0.57 & 5.70 \\
\hline $106.513+0.409 \mathrm{KAL}+1.283 \mathrm{FLL}+1.413 \mathrm{FBL}$ & 0.64 & 0.41 & 6.70 \\
\hline $116.148+1.368 \mathrm{FLL}+2.031 \mathrm{FBL}$ & 0.56 & 0.31 & 7.21 \\
\hline $77.405+0.518 \mathrm{LLR}+0.328 \mathrm{KAR}+0.825 \mathrm{FLR}+0.678 \mathrm{FBR}$ & 0.76 & 0.57 & 5.69 \\
\hline $107.132+0.415 \mathrm{KAR}+1.322 \mathrm{FLR}+1.234 \mathrm{FBR}$ & 0.63 & 0.40 & 6.75 \\
\hline $117.413+1.384$ FLR + 1.876 FBR & 0.55 & 0.30 & 7.27 \\
\hline
\end{tabular}

Table 5

Descriptive statistics of mean values of known stature and estimated stature in males, females, and a group consisting of both sexes

\begin{tabular}{|c|c|c|c|c|c|c|}
\hline Parameter & Sex & N & Min & Max & Mean & SD \\
\hline \multirow{3}{*}{ Known stature } & Male & 112 & 162 & 189 & 174.64 & 5.66 \\
\cline { 2 - 7 } & Female & 88 & 148 & 175 & 161.43 & 5.73 \\
\cline { 2 - 7 } & Combined & 200 & 148 & 189 & 168.83 & 8.69 \\
\hline \multirow{3}{*}{ Estimated stature RT } & Male & 112 & 164.05 & 191.84 & 174.59 & 3.08 \\
\cline { 2 - 7 } & Female & 88 & 154.52 & 177.31 & 165.23 & 4.59 \\
\cline { 2 - 7 } & Combined & 200 & 152.06 & 203.73 & 168.76 & 6.58 \\
\hline \multirow{3}{*}{ Estimated stature LT } & Male & 112 & 163.73 & 191.21 & 174.59 & 3.02 \\
\cline { 2 - 7 } & Female & 88 & 151.13 & 172.78 & 161.63 & 4.38 \\
\cline { 2 - 7 } & Combined & 200 & 151.46 & 202.33 & 168.78 & 6.59 \\
\hline
\end{tabular}

Paired T-test between known and estimated height

\begin{tabular}{|c|c|c|c|c|}
\hline Parameter & Sex & Mean & $\mathrm{t}$ & Sig \\
\hline \multirow{3}{*}{ Estimated stature RT } & Male & 0.47 & 0.106 & 0.916 \\
\cline { 2 - 5 } & Female & -3.80 & -9.82 & 0.000 \\
\cline { 2 - 5 } & Combined & 0.070 & 0.176 & 0.860 \\
\hline \multirow{3}{*}{ Estimated stature LT } & Male & 0.54 & 0.120 & 0.905 \\
\cline { 2 - 5 } & Female & -0.21 & -0.523 & 0.602 \\
\cline { 2 - 5 } & Combined & 0.046 & 0.116 & 0.908 \\
\hline
\end{tabular}




\section{Discussion}

Estimation of stature is a paramount task for forensic pathologist in the identification of mutilated, fragmentary and commingled human remains. The body height is estimated by using its components [6]. The variations exist between ethnic origins and racial affiliation in relation to body dimensions [1]. The present study takes this into the consideration and used similar measurements from the living people in north-west population of India. Various studies conducted on measurement of stature from lower limb parameters, took measurements from the left side of body according to the procedure described by the International Biological Program [1, 712]. It is not uncommon that a right side body part may be presented for forensic examination for its subsequent identification and stature estimation. We have taken measurements from both the right and left side of the body and try to correlate whether any significant difference is observed in estimation of stature from various lower limb dimensions of right and left side.

In our study strong positive correlation was observed between lower limb length $(r=0.65)$ and foot length $(r=0.51)$ with stature in a group consisting of both sexes, while moderate degree of association observed knee ankle length $(r=0.43)$ and foot breadth $(r=0.40$ for right side and $r=0.42$ for left side) with the stature. In females also, strong positive correlation was observed between lower limb length $(r=0.64$ for right side and $\mathrm{r}=0.62$ for left side) and foot length with ( $\mathrm{r}=0.61$ for right side and $r=0.62$ for left side), while low degree of association was observed between knee ankle length $(r=0.26)$ and foot breadth with the stature ( $\mathrm{r}=0.19$ for right side and $r=0.22$ for left side). In males, moderately strong positive correlation was observed between lower limb length ( $\mathrm{r}=0.40$ for right side and $\mathrm{r}=0.38$ for left side), knee ankle length $(r=0.30)$ and foot length $(r=0.33$ for right side and $r=0.34$ for left side) with stature, while low degree of association observed between foot breadth with the stature ( $\mathrm{r}=0.25$ for right side and $\mathrm{r}=0.26$ for left side) (Table 3). As the majority of studies have taken measurements from the left side of the body, Pearson's correlation comparison of various studies on different populations for various lower limb parameters of the left side with stature is depicted in Table 7. However Krishan et al. [2] in their study took measurements from both the right and left side of the body as done in our study. The correlation of right and left foot length with the stature in males was observed as $0.732 \& 0.741$, while that with right and left foot breadth was 0.315 and 0.324 . The correlation of right and left foot length with the stature in females was observed as $0.739 \& 0.734$, while that with right and left foot breadth was 0.294 and 0.323 . It was observed from the below depicted comparison that lower limb length and foot length exhibits strong correlation with the stature and is a better predictor of stature as compared to foot breadth and knee ankle length.

Table 7

Pearson's correlation comparison of various studies on different populations

\begin{tabular}{|c|c|c|c|c|c|c|c|c|c|c|c|c|c|}
\hline \multirow{3}{*}{ Study } & \multirow{3}{*}{$\begin{array}{l}\text { Population } \\
\text { under } \\
\text { study }\end{array}$} & \multicolumn{12}{|c|}{ Lower Limb parameter } \\
\hline & & \multicolumn{3}{|c|}{ Lower Limb Left } & \multicolumn{3}{|c|}{ Knee Ankle Left } & \multicolumn{3}{|c|}{ Foot Length Left } & \multicolumn{3}{|c|}{ Foot Breadth Left } \\
\hline & & Male & Female & $\begin{array}{l}\text { Combined } \\
\text { group }\end{array}$ & Male & Female & \begin{tabular}{l|l}
$\begin{array}{l}\text { Combined } \\
\text { group }\end{array}$ & 1
\end{tabular} & Male & Female & $\begin{array}{l}\text { Combined } \\
\text { group }\end{array}$ & Male & Female & $\begin{array}{l}\text { Combined } \\
\text { group }\end{array}$ \\
\hline $\begin{array}{l}\text { Present } \\
\text { Study }\end{array}$ & $\begin{array}{l}\text { North } \\
\text { Indian }\end{array}$ & 0.381 & 0.626 & 0.655 & 0.302 & 0.260 & 0.438 & 0.342 & 0.626 & 0.516 & 0.268 & 0.226 & 0.420 \\
\hline Xu et al.(7) & $\begin{array}{c}\text { Southern } \\
\text { China Han } \\
\text { Population } \\
\end{array}$ & 0.619 & 0.863 & - & - & - & - & 0.673 & 0.563 & - & 0.367 & 0.319 & - \\
\hline $\begin{array}{l}\text { Abu Bakar et } \\
\text { al.(8) }\end{array}$ & Malaysian & - & - & 0.81 & - & - & - & - & - & 0.69 & - & - & 0.40 \\
\hline $\begin{array}{l}\text { Bhavna and } \\
\text { Nath (9) }\end{array}$ & $\begin{array}{c}\text { Shia } \\
\text { Muslims }\end{array}$ & - & - & - & - & - & - & - & - & 0.546 & - & - & 0.383 \\
\hline Ahmed (10) & $\begin{array}{c}\text { Sudanese } \\
\text { Arab }\end{array}$ & - & - & - & - & - & - & 0.773 & 0.622 & - & 0.449 & 0.317 & - \\
\hline $\begin{array}{l}\text { Moshkdanian } \\
\text { et al. (11) }\end{array}$ & Iranian & 0.89 & - & - & - & - & - & - & 0.78 & - & - & - & - \\
\hline $\begin{array}{lll}\text { Sah } & \text { et } & \text { al. } \\
(12) & & \\
\end{array}$ & Nepal & - & - & - & - & - & - & - & 0.78 & 0.57 & 0.26 & 0.22 & - \\
\hline Nor et al. (1) & Malaysian & - & - & - & - & - & - & - & - & 0.690 & - & - & 0.517 \\
\hline
\end{tabular}

The regression based on lower limb right side in males, females and combined group showed the lowest standard error of estimation (SEE) i.e., 5.21, 4.39 and 5.94 respectively, as compared to all other parameters (Table 3).

A low SEE indicated a higher accuracy. The comparison of coefficient of determination $\left(\mathrm{R}^{2}\right)$ and standard error of estimate for various lower limb parameters of the left side in various studies on different populations is depicted in Table 8.

Lower limb length and foot length was observed to be better predictor of stature as compared to knee ankle length and foot breadth which was comparable to other study results as shown in Table 7. 
Comparison of coefficient variance and standard error of estimate of various studies

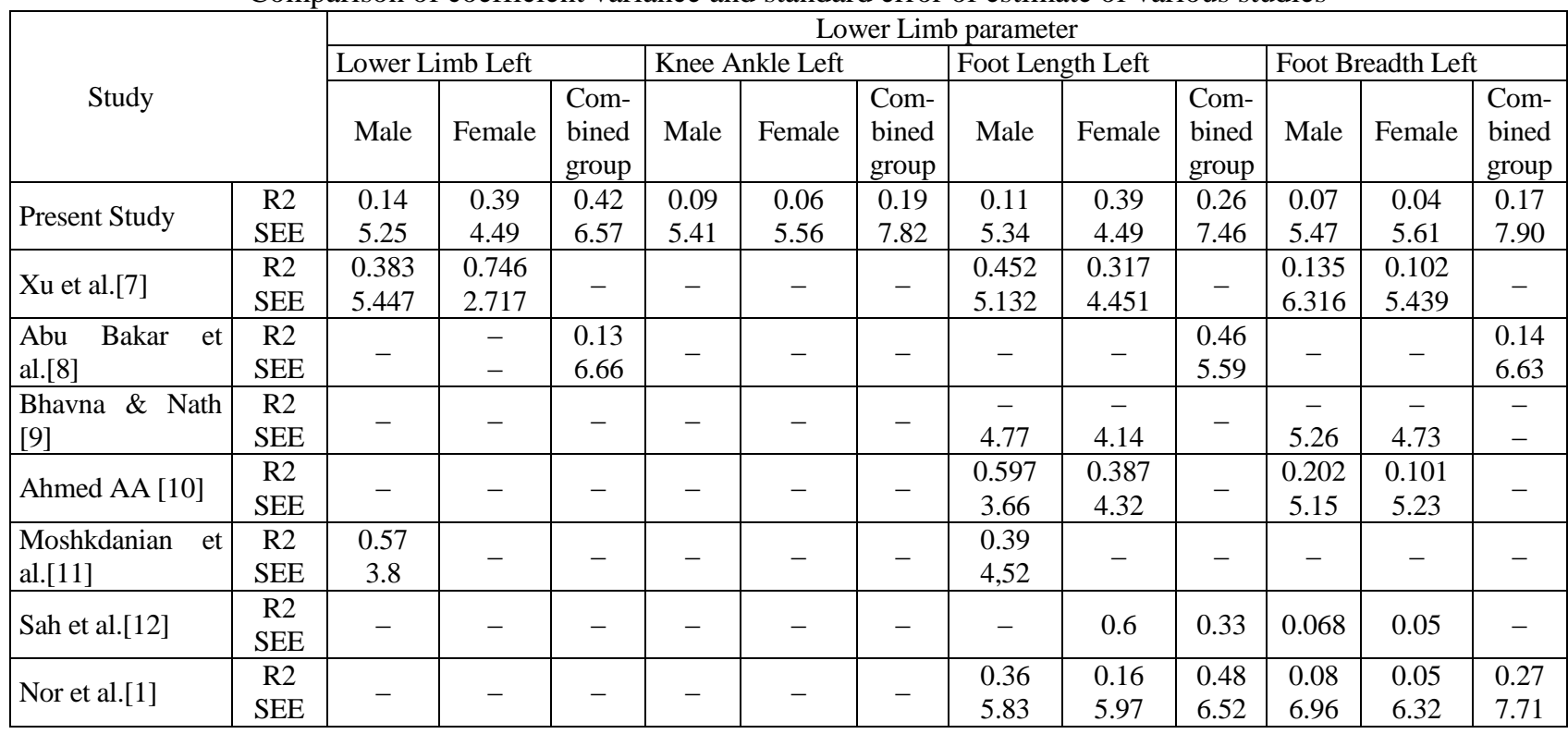

The mean difference between known stature and estimated stature in the present study was $0.05 \mathrm{~cm}$ for both right and left side in males. The mean difference between known stature and estimated stature was higher in females for the right side $(3.8 \mathrm{~cm})$ as compared to the left side $(0.20 \mathrm{~cm})$. In a group consisting of both sexes the mean difference between known stature and estimated stature was marginal ranging from 0.05 to $0.07 \mathrm{~cm}$ ) (Table 5). There was no statistically significant difference between known stature and estimated stature by using paired T-test for both right and left side in combined group and in males ( $p>0.05)$. While in females, statistically significant difference (p-value 0.000) was observed in known stature and estimated stature for right side (Table 6). Thus, the equations formulated for right and left side could be used for stature estimation in males in this particular population. However, for females left side equations could be used with greater accuracy as compared to right side. However, it is suggested that further studies with more sample size of the female population should be done to rule out the difference in stature estimation from body parts of the right and left side.

Other studies also observed that there was no significant difference between actual stature and estimated stature based on lower limb measurements by paired ttest and the equations formulated could be used to estimate stature. However, they have taken only the left side of body measurements in their study.

Study limitations. The boundaries between racial groups have been heavily influenced by migration, relocation and intermarriages leading to genetic intermixture. These facts were not considered in the present study.
Further research on the topic should be undertaken into the consideration of population migration, relocation and other factors along with larger sample size, so that the study results can be precisely generalized to the population.

\section{Conclusion}

The regressions achieved in this study had confirmed the usefulness of lower limb parameters for stature estimation in the North-west Indian population. From the parameters, lower limb length and foot length had shown strong positive correlations with stature, in accordance with that in the literature. The results of the current study depicts that the dimensions of lower limb can be used effectively for estimation of stature by forensic pathologists and investigating agencies. However, it has to bear in mind that due to innate population variations which may be attributed to genetic and environmental factors, these formulae are relevant to the population from which the data have been collected.

\section{Conflict of interest}

The authors declare that they have no conflicts of interest.

\section{Funding}

The study was performed without financial support.

\section{Acknowledgement}

The contributions of Dr Shiv Shankar, Dr Kapil Yadav, Dr Hemant, Dr Sahil Sharma in this work are sincerely appreciated and gratefully acknowledged.

\section{References}

1. Nor, F. M., Abdullah, N., Mustapa, A.-M., Qi Wen, L., Faisal, N. A., Ahmad Nazari, D. A. A. (2013). Estimation of stature by using lower limb dimensions in the Malaysian population. Journal of Forensic and Legal Medicine, 20 (8), 947-952. doi: http://doi.org/10.1016/j.jflm.2013.09.006

2. Krishan, K., Sharma, A. (2007). Estimation of stature from dimensions of hands and feet in a North Indian population. Journal of Forensic and Legal Medicine, 14 (6), 327-332. doi: http://doi.org/10.1016/j.jcfm.2006.10.008 
3. Telkkä, A. (1950). On the prediction of human stature from the long bones. Cells Tissues Organs, 9 (1-2), 103-117. doi: http://doi.org/10.1159/000140434

4. Trotter, M., Gleser, G. C. (1952). Estimation of stature from long bones of American Whites and Negroes. American Journal of Physical Anthropology, 10 (4), 463-514. doi: http://doi.org/10.1002/ajpa.1330100407

5. Agnihotri, A. K., Purwar, B., Googoolye, K., Agnihotri, S., Jeebun, N. (2007). Estimation of stature by foot length. Journal of Forensic and Legal Medicine, 14 (5), 279-283. doi: http://doi.org/10.1016/j.jcfm.2006.10.014

6. Özaslan, A., İşcan, M. Y., Özaslan, İ., Tuğcu, H., Koç, S. (2003). Estimation of stature from body parts. Forensic Science International, 132 (1), 40-45. doi: http://doi.org/10.1016/s0379-0738(02)00425-5

7. Wang, Q., Xu, L.-Y., Lei, F.-Z., Lin, J.-X., Song, L., Li, X.-Y. (2020). Stature estimation from body dimensions in Han population of Southern China. Journal of Forensic Science and Medicine, 6 (4), 126-134. doi: http://doi.org/10.4103/jfsm.jfsm_39_20

8. Abu Bakar, S. N., Aspalilah, A., AbdelNasser, I., Nurliza, A., Hairuliza, M. J., Swarhib, M. (2017). Stature Estimation from Lower Limb Anthropometry using Linear Regression Analysis: A Study on the Malaysian Population. Clinical Therapeutics, 168 (2), e84-e87.

9. Bhavna, N. S., Nath, S. (2009). Use of lower limb measurements in reconstructing stature among Shia Muslims. The Internet Journal of Biological Anthropology, 2 (2), 86-97.

10. Ahmed, A. A. (2013). Estimation of stature using lower limb measurements in Sudanese Arabs. Journal of Forensic and Legal Medicine, 20 (5), 483-488. doi: http://doi.org/10.1016/j.jflm.2013.03.019

11. Moshkdanian, G., Zadeh, S. M., Ghoroghi, F. M., Mokhtari, T., Hassanzadeh, G. (2014). Estimation of stature from the anthropometric measurement of lower limb in Iranian adults. Anatomical Sciences, 11 (3), $149-154$.

12. Sah, S. K., Karki, N., Jeelani, B. A. (2018). Estimation of Height from Foot Dimensions. Journal of Lumbini Medical College, 6 (1), 27-31. doi: http://doi.org/10.22502/jlmc.v6i1.182

Received date 10.11.2021 Accepted date 22.12.2021

Published date 30.01.2022

Hitesh Chawla, Professor, Department of Forensic Medicine and Toxicology, SHKM Government Medical College Nalhar, Haryana, India, 122107

Ashish Tyagi, Associate Professor, Department of Forensic Medicine and Toxicology, SHKM Government Medical College Nalhar, Haryana, India, 122107

Sandeep Dara, Resident, Department of Forensic Medicine and Toxicology, SHKM Government Medical College Nalhar, Haryana, India, 122107

Aravindan U., Resident, Department of Forensic Medicine and Toxicology, SHKM Government Medical College Nalhar, Haryana, India, 122107

*Corresponding author: Hitesh Chawla, e-mail: drhiteshchawla@gmail.com 